\title{
Total intravenous anaesthesia versus inhaled anaesthesia for endoscopic sinus surgery: a meta-analysis of randomized controlled trials*
}

\author{
Nadeem R. Kolia, Li-Xing Man \\ Department of Otolaryngology Head and Neck Surgery, University of Rochester, Rochester, NY, USA
}

Rhinology 57: 6, $402-410,2019$

https://doi.org/10.4193/Rhin19.171

*Received for publication:

April 25, 2019

Accepted: June 26, 2019

\begin{abstract}
Background: Total intravenous anaesthesia (TIVA) with propofol, compared to inhaled anaesthesia (IA), has been proposed to reduce bleeding and improve surgical field quality during endoscopic sinus surgery (ESS), but prior meta-analyses have not been conclusive. We performed an updated meta-analysis to determine the benefit of TIVA versus IA during ESS.
\end{abstract}

Methodology: PubMed, EMBASE, and Cochrane Library were searched for randomized controlled trials (RCTs) comparing TIVA versus IA. Demographic and outcome data were extracted from articles meeting selection criteria and analysed.

Results: We included 12 RCTs for a total of 560 patients. Preoperative characteristics were similar between the two groups. Compared to IA, TIVA improved surgical visibility, estimated blood loss (EBL), and operative time. In a subgroup analysis with remifentanil as the short-acting opioid, TIVA improved surgical visibility, EBL, and operative time. These benefits were not seen with fentanyl as the short-acting opioid.

Conclusions: TIVA with propofol, in comparison to IA, may improve surgical field quality, reduce blood loss, and decrease operative time for ESS. Remifentanil is the preferred short-acting opioid for TIVA in ESS.

Key words: endoscopic sinus surgery, inhaled anaesthesia, meta-analysis, propofol, total intravenous anaesthesia

\section{Introduction}

Endoscopic sinus surgery (ESS) is now the established modality through which a variety of pathologies of the paranasal sinuses and anterior skull base are surgically addressed. Successful and safe ESS relies upon a mastery of anatomy, the study of specific patient imaging, and maintaining a clear surgical field while operating. Blood loss during ESS obscures important landmarks the surgeon relies upon for navigation and safe dissection. Consequently, optimizing the surgical field by minimizing blood loss is an important component of ESS. Surgical principles and techniques that limit or reduce blood flow in the operative field are of the utmost importance for the surgeon to understand and master. Anaesthetic techniques and agents can also have an impact on surgical conditions and have been the topic of many discussions and investigations.
Anaesthetic agents affect the patient's systemic blood pressure as well as the local capillary beds of the surgical field. The anaesthetic technique that has shown the most promise in obtaining controlled hypotension during ESS is total intravenous anaesthetic (TIVA), rather than the more traditional and routine practice of using inhaled anaesthetics (IA). Many studies have specifically evaluated the use of propofol and a short acting opioid versus a volatile inhalational anaesthetic and a short acting opioid. Some randomized controlled trials (RCTs) on the topic have shown that TIVA is superior to IA with regards to the quality of the surgical field ${ }^{(1-4)}$. Studies have also suggested that blood loss is lower with TIVA compared to IA ${ }^{(1,3,5)}$. However, other RCTs have not shown TIVA to be superior to IA for surgical field quality and/or blood loss ${ }^{(6-12)}$.

Systematic reviews and meta-analyses on the topic have inclu- 
ded a limited number of RCTs and are inconclusive. In 2012, Kelly et al. conducted a systematic review, but did not perform a meta-analysis due to a lack of power and study heterogeneity (13). A Cochrane meta-analysis published in 2013 and updated in 2016 found TIVA improved the surgical field but did not decrease estimated blood loss (EBL) or operative time. However, the authors defined deliberate hypotension narrowly as a mean arterial pressure (MAP) between 50 and $65 \mathrm{~mm} \mathrm{Hg}$ and limited the meta-analysis to studies with that specific range as the target MAP. Only four studies met this strict criteria while an additional 10 studies were excluded for specifying a different blood pressure goal ${ }^{(14)}$. Finally, a meta-analysis of nine studies by DeConde et al. in 2013 found similar results of superior visibility scores with TIVA, but no difference in EBL or operative time ${ }^{(15)}$. A number of additional RCTs have been published after this meta-analysis, and a few previously-published RCTs were not captured by their search strategy. As no prior meta-analysis had incorporated these RCTs, we set out to perform an updated meta-analysis comparing TIVA with IA for ESS. Furthermore, our meta-analysis is the first to include a subgroup analysis on both the short acting opioid and the inhaled anaesthetic.

\section{Methods}

\section{Eligibility criteria}

We analysed randomized controlled trials comparing total intravenous anaesthesia to inhalational anaesthesia in patients undergoing endoscopic sinus surgery. TIVA was defined as a combination of propofol and a short acting opiate, while IA was defined as a combination of a volatile anaesthetic and a short acting opiate. Trials which utilized a different short acting opiate in the TIVA and IA groups were excluded. Trials could include patients of any age. Trials were not restricted by publication date or status, but were limited to those available in the English language.

\section{Search criteria}

Electronic searches were conducted of the PubMed, EMBASE, and Cochrane Library databases. The search was performed on September 18, 2018 and updated on April 14, 2019. The exact search query utilized was "(endoscopic sinus surgery) AND propofol AND random* AND (desflurane OR isoflurane OR sevoflurane)". No additional search filters were utilized in any database. The title and abstract of the search results were independently reviewed by both authors (NRK and LM) to determine if they satisfied our inclusion and exclusion criteria. Any discrepancies between the authors were resolved by consensus. Duplicate results among the three database searches were removed. The full-text manuscripts of all remaining studies were obtained and further reviewed for eligibility. The reference lists of included articles were also searched for additional studies.

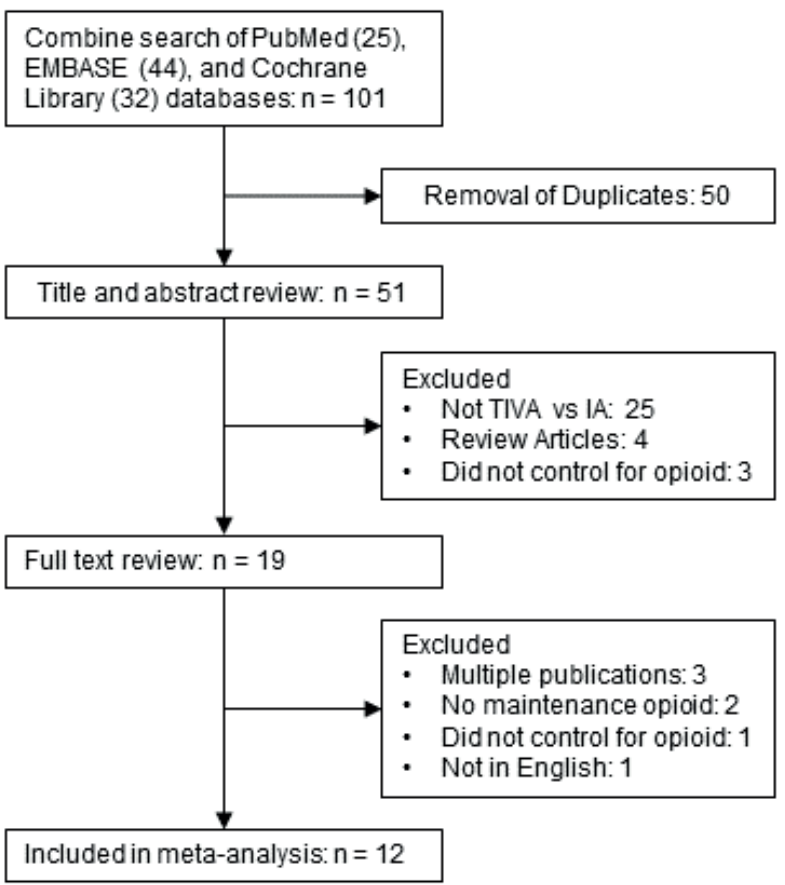

Figure 1. Flow diagram of study selection process.

\section{Data extraction}

Data was extracted from the articles by both authors independently using a data spreadsheet template. Differences were resolved by consensus. The primary outcomes were surgical field quality and EBL. The secondary outcomes were operative time, anaesthesia time, MAP, and heart rate. In addition to the characteristics of each study, demographic information was also extracted, including age, gender, weight, and preoperative Lund-Mackay score.

\section{Quality analysis}

Each included study was qualitatively evaluated for the risk of bias in seven domains: random sequence generation, allocation concealment, blinding of participants and personal, binding of outcome assessment, incomplete outcome data, selective reporting, and other. The risk of bias across studies with evaluated with a forest plot for the primary outcomes.

\section{Statistical analysis}

The principal summary measure was the mean difference in outcomes comparing TIVA to IA. The median was used as an approximation of the mean when studies did not report the mean. For the study by Pavlin et al. ${ }^{(10)}$, the mean was calculated from a histogram assuming a uniform distribution within the histogram groups. If the standard deviation was not reported, it was either calculated from the interquartile range or from the $p$-value, with the assumption the data followed a normal distribution. For the study by Yoo et al. ${ }^{(12)}$, we received standard deviation data from personal communications with the authors. Their study had 
Table 1. Study characteristics.

\begin{tabular}{|c|c|c|c|c|c|c|c|c|c|c|}
\hline Author, Year & Visibility Scale & $\begin{array}{l}\text { BP Goal } \\
\text { (mmHg) }\end{array}$ & Opioid & $\begin{array}{c}\text { Inhaled } \\
\text { Anaesthetic }\end{array}$ & Group & $\mathbf{N}$ & $\begin{array}{c}\text { Age } \\
\text { (years) }\end{array}$ & Male & $\begin{array}{l}\text { Weight } \\
\text { (kg) }\end{array}$ & $\begin{array}{l}\text { LM } \\
\text { Score }\end{array}$ \\
\hline \multirow{2}{*}{ Pavlin et al. $1999^{(10)}$} & \multirow{2}{*}{$\begin{array}{l}\text { Custom: } \\
\text { 1-4 per sinus }\end{array}$} & \multirow{2}{*}{ MAP 65-80 } & \multirow{2}{*}{ Alfentanil } & \multirow{2}{*}{ Isoflurane } & IA & 26 & 43 & $42 \%$ & 78 & \\
\hline & & & & & TIVA & 30 & 42 & $60 \%$ & 84 & \\
\hline \multirow{2}{*}{ Sivaci et al. $2004^{(11)}$} & \multirow{2}{*}{ None } & \multirow{2}{*}{ None } & \multirow{2}{*}{ Fentanyl } & \multirow{2}{*}{ Sevoflurane } & IA & 16 & 33 & & 70 & \\
\hline & & & & & TIVA & 16 & 32 & & 68 & \\
\hline \multirow{2}{*}{ Beule et al. $2007^{(7)}$} & \multirow{2}{*}{ VAS } & \multirow{2}{*}{$\begin{array}{l}\text { SBP } 70-140 \\
\text { DBP 50-90 }\end{array}$} & \multirow{2}{*}{ Fentanyl } & \multirow{2}{*}{ Sevoflurane } & IA & 22 & 46 & $64 \%$ & 80 & 15 \\
\hline & & & & & TIVA & 24 & 43 & $67 \%$ & 79 & 15 \\
\hline \multirow{2}{*}{ Ahn et al. $2008^{(1)}$} & \multirow{2}{*}{ VAS } & \multirow{2}{*}{ MAP 70-80 } & \multirow{2}{*}{ Remifentanil } & \multirow{2}{*}{ Sevoflurane } & & 18 & 41 & $83 \%$ & 69 & 14 \\
\hline & & & & & TIVA & 20 & 49 & $70 \%$ & 70 & 14 \\
\hline \multirow{2}{*}{ Yoo et al. $2010^{(12)}$} & \multirow{2}{*}{ Boezaart } & \multirow{2}{*}{ MAP 65} & \multirow{2}{*}{ Remifentanil } & \multirow{2}{*}{$\begin{array}{l}\text { Sevoflurane/ } \\
\text { Desflurane }\end{array}$} & $\mathrm{IA}$ & 40 & 43 & $55 \%$ & 65 & 6 \\
\hline & & & & & TIVA & 20 & 37 & $75 \%$ & 65 & 7 \\
\hline \multirow{2}{*}{ Ankichetty et al. 2011} & \multirow{2}{*}{ Boezaart } & \multirow{2}{*}{ MAP 60-70 } & \multirow{2}{*}{ Fentanyl } & \multirow{2}{*}{ Isoflurane } & IA & 20 & 34 & $65 \%$ & 62 & \\
\hline & & & & & TIVA & 20 & 32 & $55 \%$ & 54 & \\
\hline \multirow{2}{*}{ Cho et al. $2012^{(2)}$} & 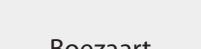 & & & & IA & 32 & 42 & $53 \%$ & 67 & 13 \\
\hline & Boezaart & MAP /0-80 & Remıtentanıl & Destlurane & TIVA & 36 & 44 & $50 \%$ & 63 & 13 \\
\hline Gomez-Rivera et al 2012 (9) & Boezaart & MAP 70-80 & Remifentanil & Sevoflurane & IA & 11 & 50 & $55 \%$ & & 15 \\
\hline Gomez-RIvera et al. 2012 & Boezaart & IVIAP /0-80 & Remitentanıl & sevotiurane & TIVA & 12 & 51 & $58 \%$ & & 7 \\
\hline Chaaban et al $2013^{(8)}$ & None & $S B P<100$ & Fentanvl & Sevoflurane & $\mathrm{IA}$ & 15 & 43 & $53 \%$ & & 13 \\
\hline Cnadoan et al. 2013 & None & SBP $<100$ & rentanyi & sevomurane & TIVA & 18 & 41 & $50 \%$ & & 14 \\
\hline Marzhan et al 2013 (3) & VAS & MAP 70-80 & Bemifentanil & Isoflurane & IA & 22 & 34 & $55 \%$ & & \\
\hline 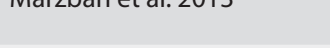 & כול & 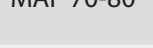 & netinentarmi & 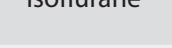 & TIVA & 22 & 32 & $64 \%$ & & \\
\hline Milonckiet al 2012 (5) & VAS & МАР 6070 & Pomifontanil & Sevoflumane & IA & 30 & & $70 \%$ & & \\
\hline 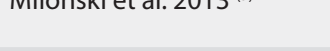 & VAS & IVIAR OU- OU & Remırentanı & sevoriurane & TIVA & 30 & & $57 \%$ & & \\
\hline Little et al. $2018^{(4)}$ & Wormald & MAP 60-70 & Remifentanil & Desflurane & IA & 15 & 51 & $73 \%$ & & \\
\hline Little et al. 2018 & vormaid & IVIAP OU-/O & Remıtentanı & Destiurane & TIVA & 15 & 45 & $40 \%$ & & \\
\hline
\end{tabular}

LM = Lund-Mackay; BP = Blood Pressure; DBP = Diastolic Blood Pressure; MAP = Mean Arterial Pressure; SBP = Systolic Blood Pressure; IA = Inhaled Anaesthetic; TIVA = Total Intravenous Anaesthesia; VAS = Visual Analog Scale.

two IA groups and one TIVA group. The data from the two IA groups were combined for comparison against the TIVA group. As different scales were used by different studies to grade the surgical field, the standardized mean difference (SMD) was used as the summary statistic for surgical field visibility. For all other outcomes, the mean difference (MD) was used as the summary statistic. Data analysis was performed with Review Manager (RevMan) 5 by The Cochrane Collaboration, using a random effects model.

\section{Results}

\section{Study selection}

A search of PubMed, EMBASE, and Cochrane Library databases yielded a total of 101 results, 51 of which were unique. After title and abstract review, 19 citations qualified for full-text review. However, this only represented 16 unique studies as three studies had a second citation for an abstract published independently prior to manuscript publication. One study was excluded as it was not written in English. Two studies were excluded as it did not meet our definition of TIVA because a short acting opioid was not used as a part of maintenance anaesthesia. One study was excluded because it did not control for the short acting opioid used in the TIVA and IA groups. Thus 12 studies satisfied the inclusion and exclusion criteria and were included in the meta-analysis ${ }^{(1-12)}$. No additional studies were identified by checking the references of relevant papers. A flow diagram for study selection is presented in Figure 1.

\section{Study characteristics}

Study characteristics and demographic data are summarized in Table 1, while outcome data is summarized in Table 2. The included studies involved a total of 560 patients. Average age of patients varied from 32 to 51 years old. When reported, average Lund-Mackay scores generally ranged from 13 to 15 . Two studies had patient groups with an average Lund-Mackay score of 6 or $7^{(9,12)}$. Sivaci et al. was the only study not to specify an intraope- 
Table 2. Study data.

\begin{tabular}{|c|c|c|c|c|c|c|c|}
\hline Author, Year & Group & $\begin{array}{l}\text { Visibility } \\
\text { Score }\end{array}$ & EBL $(\mathrm{mL})$ & $\begin{array}{l}\text { Operative } \\
\text { Time (min) }\end{array}$ & $\begin{array}{l}\text { Anaesthesia } \\
\text { Time (min) }\end{array}$ & $\begin{array}{c}\text { Mean } \\
\text { Arterial Pres- } \\
\text { sure }(\mathrm{mmHg})\end{array}$ & $\begin{array}{l}\text { Heart Rate } \\
\text { (bpm) }\end{array}$ \\
\hline \multirow{2}{*}{ Pavlin et al. 1999 (10) } & IA & 1.9 & 147 & 130 & & 71 & \\
\hline & TIVA & 1.7 & 189 & 136 & & 74 & \\
\hline \multirow{2}{*}{ Sivaci et al. $2004^{(11)}$} & IA & & 297 & 68 & & & \\
\hline & TIVA & & 128 & 63 & & & \\
\hline \multirow{2}{*}{ Beule et al. $2007^{(7)}$} & IA & 3.7 & 300 & 73 & & 70 & 64 \\
\hline & TIVA & 4.3 & 277 & 71 & & 72 & 65 \\
\hline \multirow{2}{*}{ Ahn et al. $2008^{(1)}$} & IA & 4.8 & 211 & 99 & 127 & 73 & 70 \\
\hline & TIVA & 2.9 & 26 & 83 & 119 & 73 & 62 \\
\hline \multirow{2}{*}{ Yoo et al. $2010^{(12)}$} & IA & 2.1 & & 83 & 109 & 67 & 74 \\
\hline & TIVA & 2.1 & & 83 & 107 & 69 & 75 \\
\hline \multirow{2}{*}{ Ankichetty et al. $2011^{(6)}$} & $\mathrm{IA}$ & 1.6 & 133 & 131 & & & \\
\hline & TIVA & 1.3 & 109 & 98 & & & \\
\hline \multirow{2}{*}{ Cho et al. $2012^{(2)}$} & IA & 2.7 & & 32 & & 73 & 66 \\
\hline & TIVA & 2.3 & & 33 & & 73 & 65 \\
\hline \multirow{2}{*}{ Gomez-Rivera et al. $2012^{(9)}$} & IA & 1.8 & 355 & 216 & 282 & & \\
\hline & TIVA & 2.1 & 152 & 144 & 198 & & \\
\hline \multirow{2}{*}{ Chaaban et al. $2013^{(8)}$} & IA & 7.1 & 131 & 117 & 164 & 81 & 75 \\
\hline & TIVA & 6.8 & 194 & 135 & 181 & 88 & 72 \\
\hline \multirow{2}{*}{ Marzban et al. $2013^{(3)}$} & IA & 3.0 & 291 & 124 & & & \\
\hline & TIVA & 1.9 & 155 & 96 & & & \\
\hline \multirow{2}{*}{ Milonski et al. $2013^{(5)}$} & $\mathrm{IA}$ & & 340 & 79 & 113 & & \\
\hline & TIVA & & 225 & 67 & 104 & & \\
\hline \multirow{2}{*}{ Little et al. $2018^{(4)}$} & IA & 5.5 & 285 & 106 & & 63 & 65 \\
\hline & TIVA & 4.2 & 245 & 112 & & 68 & 76 \\
\hline
\end{tabular}

EBL = Estimated Blood Loss, IA = Inhaled Anaesthesia; TIVA = Total Intravenous Anaesthesia; $b p m=$ beats per minute.

rative blood pressure goal as part of their protocol ${ }^{(11)}$, though there was variability among the other studies in what the goal was and how it was specified. Most studies used either fentanyl or remifentanil as the short acting opioid agent, while one study used alfentanil. For the inhaled anaesthetic, half of the studies used sevoflurane, while the other half were split evenly between isoflurane and desflurane.

\section{Risk of bias}

Our analysis of the risk of bias in individual studies is summarised in Figure 2. The risk of selection bias was unclear in some studies because not enough detail was provided on how random sequence for allocation was generated or concealed. Similarly, with regards to performance and detection bias, some studies did not specify if and how surgeons were blinded to the type of anaesthesia administered. We found only one instance of a high risk of bias across all studies. Ahn et al. excluded two patients from the IA group from analysis because they were con- verted to TIVA intraoperatively upon surgeon request because of poor surgical conditions. However, since this introduces a risk of bias favouring $I A$, and would only result in an underestimation of the benefit of TIVA, the study was not excluded.

\section{Results of individual studies}

Overall effects estimates are reported in Table 3. There was variability in the demographic and outcome data that was reported in each study and available for analysis. In terms of demographic data, 11 studies reported on age, while 11 reported on gender, 7 on weight, and 6 on preoperative Lund-Mackay score. There was no difference in any of these measures between the TIVA and IA groups pooled across all studies. Of the 12 studies, 10 graded visibility of the surgical field. Of these, 1 study reported both a Wormald score ${ }^{(16)}$ and a Boezaart score ${ }^{(17)}$, while 4 reported only a Boezaart score, 4 reported on a Visual Analog Scale, and one study used a custom 1-4 ordinal scale graded per sinus. All 12 studies reported operative time, while 9 studies reported on 


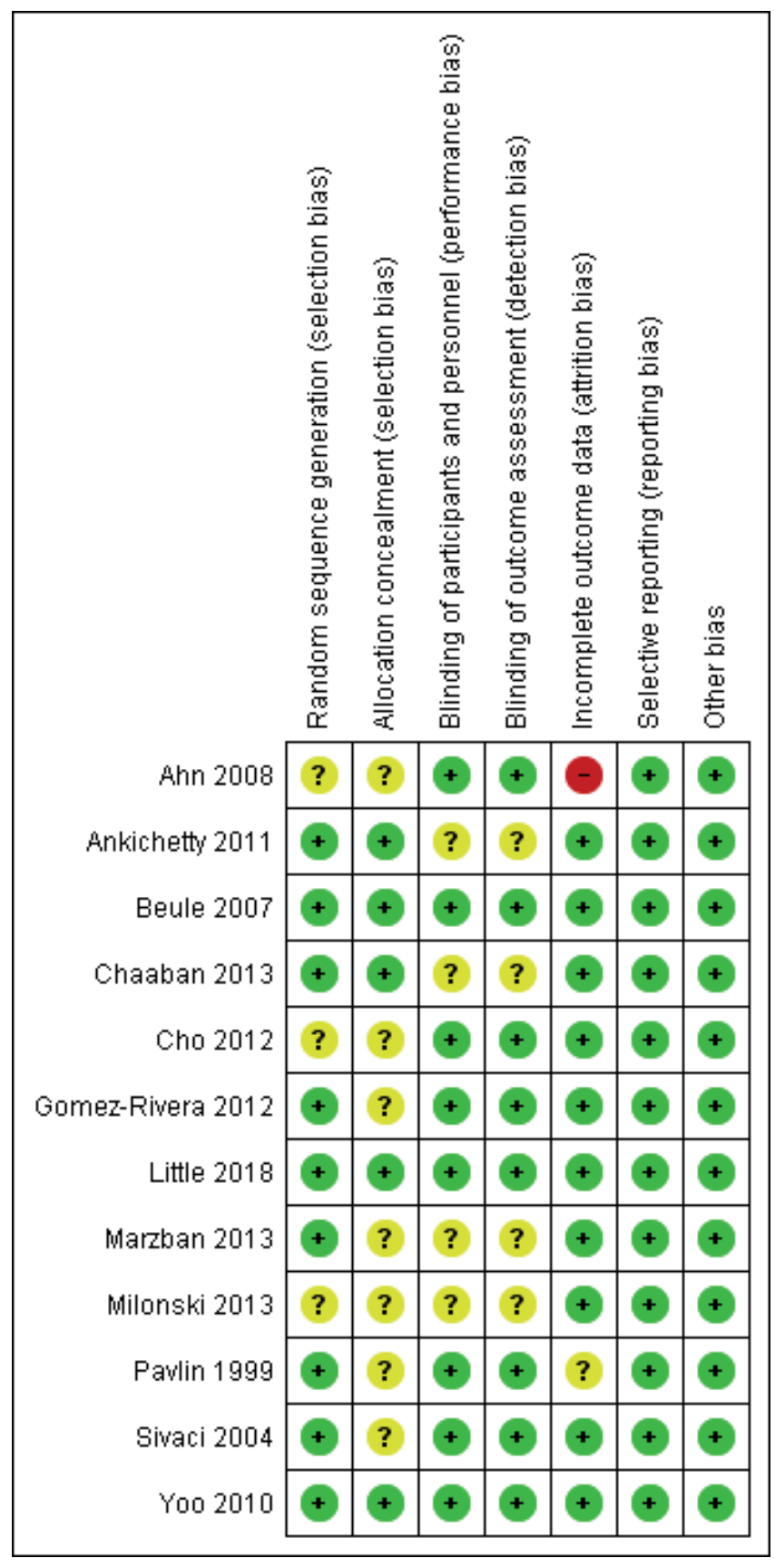

Figure 2. Summary of risk of bias assessment.

$\mathrm{EBL}, 5$ on anaesthesia time, 7 on MAP, and 6 on heart rate.

\section{Results of pooled analysis}

In the pooled analysis, there was no difference between IA and TIVA regarding anaesthesia time or heart rate. There was a statistically significant difference with regards to surgical visibility, EBL, operative time, and MAP. Compared to IA, TIVA improved surgical visibility (SMD $-0.4,95 \% \mathrm{Cl}-0.6$ to $-0.2, \mathrm{p}=0.001$ ), EBL (MD $-61 \mathrm{~mL}, 95 \% \mathrm{Cl}-117$ to $-5 \mathrm{~mL}, \mathrm{p}=0.03$ ), and operative time (MD -7.8 minutes, $95 \% \mathrm{Cl}-15.6$ to -0.0 minutes, $\mathrm{p}=0.05$ ). With TIVA, the MAP was slightly higher than with IA (MD $1.9 \mathrm{mmHg}$,
$95 \% \mathrm{Cl} 0.6$ to $3.2 \mathrm{mmHg}, \mathrm{p}=0.005)$. Summary data, effect estimates, confidence intervals, and weight for each study for surgical visibility and EBL are shown in Figures 3 and 4, respectively. There was low heterogeneity among the studies for the outcome of surgical visibility $\left(I^{2}=31 \%\right)$, while there was greater heterogeneity with regards to $\mathrm{EBL}\left(\mathrm{I}^{2}=73 \%\right)$. Funnel plots were created for the primary outcomes of surgical visibility (Figure 5), and EBL (Figure 6). Neither of these funnel plots demonstrated gross asymmetries.

Results of subgroup analysis

A subgroup analysis of inhalational agent was performed. The results of the subgroup analysis are shown in Table 4. Visibility was superior with TIVA compared to isoflurane (SMD - - . .5, 95\% $\mathrm{Cl}-0.8$ to $-0.1, \mathrm{p}=0.01$ ), and compared to desflurane (SMD -0.5, $95 \% \mathrm{Cl}-0.9$ to $-0.1, \mathrm{p}=0.02)$, but not compared to sevoflurane (SMD $-0.2,95 \% \mathrm{Cl}-0.6$ to $0.2, \mathrm{p}=0.27$ ). Conversely, EBL was lower with TIVA compared to sevoflurane (MD -101 mL, 95\% $\mathrm{Cl}-176$ to $-27 \mathrm{~mL}, \mathrm{p}=0.008$ ), but not compared to isoflurane (MD -39 mL, $95 \% \mathrm{Cl}-129$ to $51 \mathrm{~mL}, \mathrm{p}=0.40$ ). There were an insufficient number of studies to compare TIVA to desflurane with regards to EBL. Operative time was not reduced with TIVA compared to any of the inhaled anaesthetics.

A subgroup analysis was also performed on short acting opioid. As alfentanil was used in only two studies, it was not included. The results of this subgroup analysis are shown in Table 5. TIVA with remifentanil was superior to IA with regards to visibility (SMD - $0.5,95 \% \mathrm{Cl}-0.9$ to $-0.2, \mathrm{p}=0.001$ ) and EBL (MD - $125 \mathrm{~mL}$, $95 \% \mathrm{Cl}-174$ to $-76 \mathrm{~mL}, \mathrm{p}<0.00001$ ), but not operative time (MD -12.2 minutes, $95 \% \mathrm{Cl}-24.0$ to -0.2 minutes, $\mathrm{p}=0.05$ ). TIVA with fentanyl was not superior to IA with regards to visibility (SMD $-0.1,95 \% \mathrm{Cl}-0.5$ to $0.3, \mathrm{p}=0.55), \mathrm{EBL}(\mathrm{MD}-44 \mathrm{~mL}, 95 \% \mathrm{Cl}-146$ to $59 \mathrm{~mL}, \mathrm{p}=0.4$ ), or operative time (MD -7.1 minutes, $95 \% \mathrm{Cl}$ -21.7 to 7.5 minutes, $p=0.34$ ).

\section{Discussion}

\section{Summary of evidence}

Our pooled analysis found that TIVA improved visibility of the surgical field. The premise is that a better surgical field allows for more thorough surgery and a lower risk of complications. These are two outcomes of interest but are difficulty to study directly because: (1) The completeness of surgical dissection is difficult to measure, and (2) A very large number of patients would be needed to show statistical differences in complication rates due to their infrequent occurrence in sinus surgery.

The prevalent theory behind the benefit of TIVA compared to IA then is that the quality of the surgical field is improved by a reduction in blood loss. Our pooled analysis did find that TIVA reduced $E B L$ compared to IA, although there was considerable heterogeneity in this outcome $\left(I^{2}=73 \%\right)$ that is likely multifactorial. There was considerable variability in the sophistication 


\begin{tabular}{|c|c|c|c|c|c|c|c|c|c|c|c|c|}
\hline \multirow[b]{2}{*}{ Study or Subgroup } & \multicolumn{2}{|c|}{ TIVA } & \multicolumn{4}{|c|}{ IA } & \multicolumn{3}{|c|}{ Mean Difference } & \multirow{2}{*}{\multicolumn{2}{|c|}{$\begin{array}{c}\text { Mean Difference } \\
\text { IV, Random, } 95 \% \mathrm{Cl}[\mathrm{min}]\end{array}$}} & \\
\hline & Mean [min] & SD [min] & Total & Mean [min] & SD [min] & Total & Weight & IN, Random, 95\% Cl [min] & & & & \\
\hline Ahn 2008 & 26.28 & 47.42 & 20 & 211.2 & 170.77 & 18 & $12.2 \%$ & $-184.92[-266.50,-103.34]$ & & & & \\
\hline Ankichetty 2011 & 109 & 82.96 & 20 & 132.5 & 92.15 & 20 & $14.3 \%$ & $-23.50[-77.84,30.84]$ & & & 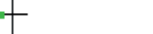 & \\
\hline Beule 2007 & 276.9 & 201.3 & 24 & 300.1 & 168.5 & 22 & $10.3 \%$ & $-23.20[-130.17,83.77]$ & & & & \\
\hline Chaaban 2013 & 194.4 & 197.2828 & 18 & 131 & 93.3389 & 15 & $10.6 \%$ & $63.40[-39.25,166.05]$ & & & & \\
\hline Gomez-Rivera 2012 & 152 & 161 & 12 & 355 & 393 & 11 & $3.9 \%$ & $-203.00[-452.47,46.47]$ & & & . & \\
\hline Little 2018 & 245 & 147.1 & 15 & 285 & 110.9 & 15 & $11.3 \%$ & $-40.00[-133.23,53.23]$ & & & - & \\
\hline Marzban 2013 & 155 & 143.4779 & 22 & 291.3 & 143.4779 & 22 & $12.0 \%$ & $-136.30[-221.09,-51.51]$ & & & & \\
\hline Milonski 2013 & 225 & 91.7 & 30 & 340 & 150.5 & 30 & $13.6 \%$ & $-115.00[-178.06,-51.94]$ & & & & \\
\hline Pavlin 1999 & 189 & 166.9617 & 30 & 147 & 166.9617 & 26 & $11.8 \%$ & $42.00[-45.68,129.68]$ & & & & \\
\hline Total $(95 \% \mathrm{Cl})$ & & & 191 & & & 179 & $100.0 \%$ & $-61.08[-117.17,-4.99]$ & & & & \\
\hline $\begin{array}{l}\text { Heterogeneity: } \text { Tau }^{2}= \\
\text { Test for overall effect: }\end{array}$ & $\begin{array}{l}4967.66 ; \mathrm{Chi}^{2} \\
=2.13(\mathrm{P}=0\end{array}$ & $\begin{array}{l}=29.40, \\
.03)\end{array}$ & $8(\mathrm{P}=$ & 0003 & $3 \%$ & & & & -500 & $\begin{array}{l}-250 \\
\text { Favors TIVA }\end{array}$ & ${ }_{\text {Favors IA }}^{250}$ & 500 \\
\hline
\end{tabular}

Figure 3. Visibility score forest plot.

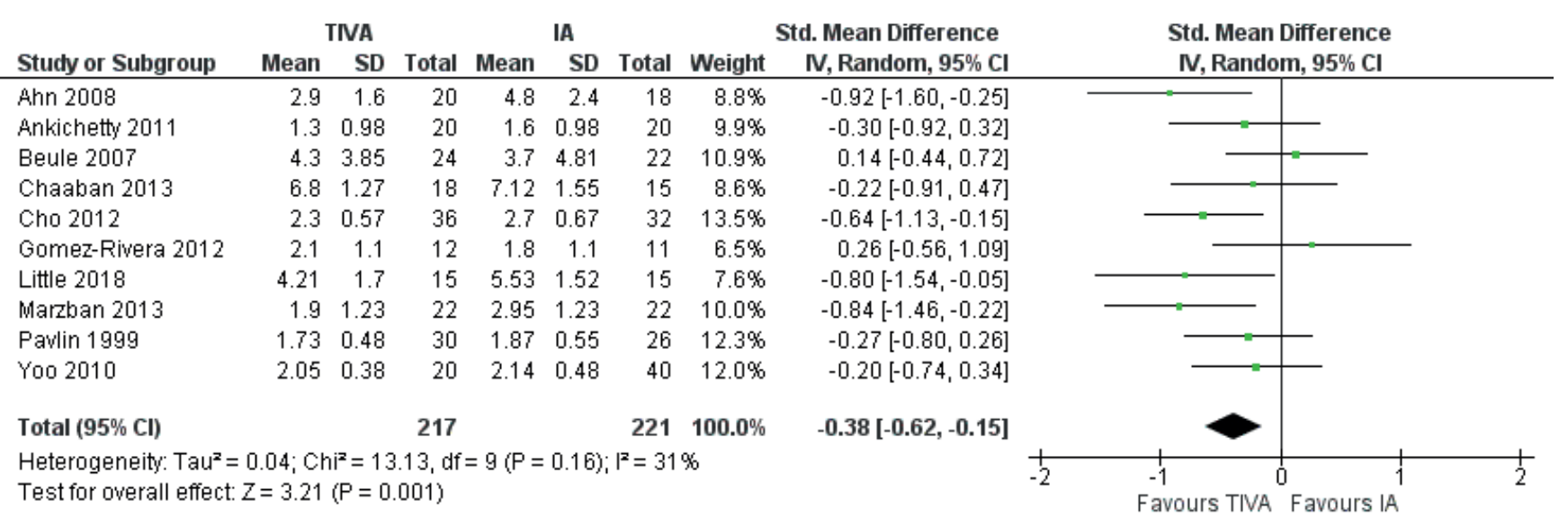

Figure 4. Estimated blood loss forest plot.

of the technique used to estimate blood loss, from simply subtracting the volume irrigated from the volume suctioned to measuring concentrations of haemoglobin to centrifuging out tissue parts from the suction canister. Nonetheless our results support the theory that TIVA improves surgical field quality by reducing blood loss.

The reduction in blood loss does not come from a difference in the patient's systemic hemodynamics. In our meta-analysis there was no difference in heart rate between the TIVA and IA groups. With regards to MAP, the pooled analysis showed that MAP was actually statistically higher with TIVA than with IA, by $1.9 \mathrm{mmHg}$. This is a negligible clinical difference, but if patient hemodynamics accounted for the difference between TIVA and IA then we would expect, if anything, to see IA superior to TIVA.

The theoretical benefit of propofol for endoscopic surgery does have a physiological basis. The benefit of propofol over inhaled anaesthetic lies in how controlled hypotension is achieved, and specifically the differential effect of propofol on central and peripheral circulation compared to inhaled anaesthetics. IA and propofol both cause peripheral vasodilation. However inhaled anaesthetics do so by relaxing pre-capillary sphincters in the mucosa, thereby increasing blood flow to the surgical field ${ }^{(18)}$. Propofol acts by depressing central sympathetic tone. Because it does not directly affect peripheral vasculature, local and topical adrenergic medications can maintain pre-capillary sphincter tone and decrease blood flow to the surgical field ${ }^{(19)}$. Propofol also has a favourable effect on central circulation. It depresses cerebral blood flow and thus decreases arterial flow to the ethmoids ${ }^{(20,21)}$. In contrast, inhaled anaesthetics cause central vasodilation, again increasing blood flow to the ethmoids and surgical field ${ }^{(21)}$. Compared to inhaled anaesthetics, propofol can theoretically achieve systemic hypotension with a vasoconstricted surgical field.

Our pooled analysis found that TIVA resulted in a reduction in operative time compared to IA, even though there was no significant difference in the severity of sinus disease by LundMackay score. This is an important outcome, as it suggests that the improvement in the surgical field quality seen in TIVA may translate to reduced operative time. Improvement in surgical field quality may have allowed surgeons to work more efficiently by reducing the need for suctioning to clear blood from the surgical field. While an improvement by 7.8 minutes represents a small reduction in operating time, the significance of this and whether it translates to increased operational efficiency or lower cost may warrant further investigation.

Our subgroup analysis of inhaled anaesthetic agents demonstrated TIVA to be superior to isoflurane and desflurane in surgical visibility, and superior to sevoflurane in operative time. 
Table 3. Overall effects.

\begin{tabular}{|c|c|c|c|c|c|}
\hline & Studies & TIVA Participants & IA Participants & $\begin{array}{c}\text { TIVA - IA Estimate } \\
{[95 \% \mathrm{CI}]}\end{array}$ & $\mathbf{p}$ \\
\hline \multicolumn{6}{|l|}{ Covariates } \\
\hline Age (years) & 11 & 218 & 222 & $-1.2[-3.6,1.3]^{\#}$ & 0.36 \\
\hline Gender & 11 & 247 & 251 & $1.1[0.8,1.7]$ & 0.48 \\
\hline Weight (kg) & 7 & 166 & 174 & $-1.8[-5.2,1.6]$ & 0.31 \\
\hline Lund-Mackay Score & 6 & 130 & 138 & $-0.1[-0.9,0.8]$ & 0.89 \\
\hline \multicolumn{6}{|l|}{ Outcomes } \\
\hline Visibility Score & 10 & 217 & 221 & $-0.4[-0.6,-0.2]$ & 0.001 \\
\hline Estimated Blood Loss (mL) & 9 & 191 & 179 & $-61[-118,-5]$ & 0.03 \\
\hline Operative Time (min) & 12 & 263 & 267 & $-7.8[-15.6,-0.0]$ & 0.05 \\
\hline Anaesthesia Time (min) & 5 & 100 & 114 & $-6.9[-19.1,5.4]$ & 0.27 \\
\hline Mean Arterial Pressure $(\mathrm{mmHg})$ & 7 & 163 & 168 & $1.9[0.6,3.2]$ & 0.005 \\
\hline Heart Rate (bpm) & 6 & 133 & 142 & $-0.1[-5.2,5.1]$ & 0.98 \\
\hline
\end{tabular}

IA = inhaled anaesthesia; TIVA = total intravenous anaesthesia; bpm = beats per minute; ${ }^{*}$ Odds Ratio.

Table 4. Subgroup analysis by inhaled anaesthetic.

\begin{tabular}{|c|c|c|c|c|c|c|c|c|c|}
\hline \multirow[b]{2}{*}{ Outcome } & \multicolumn{3}{|c|}{ Sevoflurane } & \multicolumn{3}{|c|}{ Isoflurane } & \multicolumn{3}{|c|}{ Desflurane } \\
\hline & $\mathbf{n}$ & Effect & $\mathbf{p}$ & $\mathbf{n}$ & Effect & $\mathbf{p}$ & $n$ & Effect & $\mathbf{p}$ \\
\hline Visibility & 5 & $-0.2[-0.6,0.2]$ & 0.27 & 3 & $-0.5[-0.8,-0.1]$ & 0.01 & 3 & $-0.5[-0.9,-0.1]$ & 0.02 \\
\hline Estimated Blood Loss (mL) & 6 & $-101[-176,-27]$ & 0.008 & 3 & $-39[-129,51]$ & 0.40 & 1 & - & - \\
\hline Operative Time (min) & 7 & $-7.0[-14.4,0.3]$ & 0.06 & 3 & $-20.3[-40.8,0.4]$ & 0.05 & 3 & $1.1[-3.4,5.7]$ & 0.62 \\
\hline
\end{tabular}

Table 5. Subgroup analysis by short acting opioid.

\begin{tabular}{|c|c|c|c|c|c|c|}
\hline \multirow[b]{2}{*}{ Outcome } & \multicolumn{3}{|c|}{ Fentanyl } & \multicolumn{3}{|c|}{ Remifentanil } \\
\hline & $n$ & Effect & $\mathbf{p}$ & $\mathbf{n}$ & Effect & $\mathbf{p}$ \\
\hline Visibility & 3 & $-0.1[-0.5,0.3]$ & 0.55 & 6 & $-0.5[-0.9,-0.2]$ & 0.001 \\
\hline Estimated Blood Loss (mL) & 4 & $-44[-146,59]$ & 0.40 & 5 & $-125[-174,-76]$ & $<0.00001$ \\
\hline Operative Time (min) & 4 & $-7.1[-21.7,7.5]$ & 0.34 & 7 & $-12.2[-24.1,-0.2]$ & 0.05 \\
\hline
\end{tabular}

With these mixed results, we are unable to conclude that TIVA is superior to only a particular IA agent. While TIVA was not statistically superior to any one of the IAs with regards to EBL in the subgroup analysis, it was superior to IA when the subgroups were combined. This suggests that a statistical difference was not seen for the subgroups individually because of a lack of power.

The subgroup analysis based upon the short acting opioid provided more consistent results. Across all three of our primary outcomes, TIVA was superior to IA when remifentanil was used as the short acting opioid, but not when fentanyl was utilized. Remifentanil may be superior to fentanyl as a short acting opioid adjunct regardless of whether propofol or IA agents are being used. The combination of propofol and remifentanil has been shown to reduce intraoperative bleeding compared to propofol and fentanyl in sagittal split osteotomies ${ }^{(22)}$ and endoscopic pituitary surgery ${ }^{(23)}$. As an adjunct to sevoflurane, remifentanil has been shown to be better than fentanyl in reducing intraoperative bleeding during spinal surgery ${ }^{(24)}$. However, our results suggest that there is some synergist effect from the combination of propofol and remifentanil that does not exist with remifentanil and IA. This has previously also been shown for lumbar spine fixation surgery ${ }^{(24)}$.

Our result for surgical field quality confirms a previous metaanalysis on this topic by DeConde et al., which found that TIVA improved surgical visibility score by 1.04 on a 10 point scale ( $p$ 


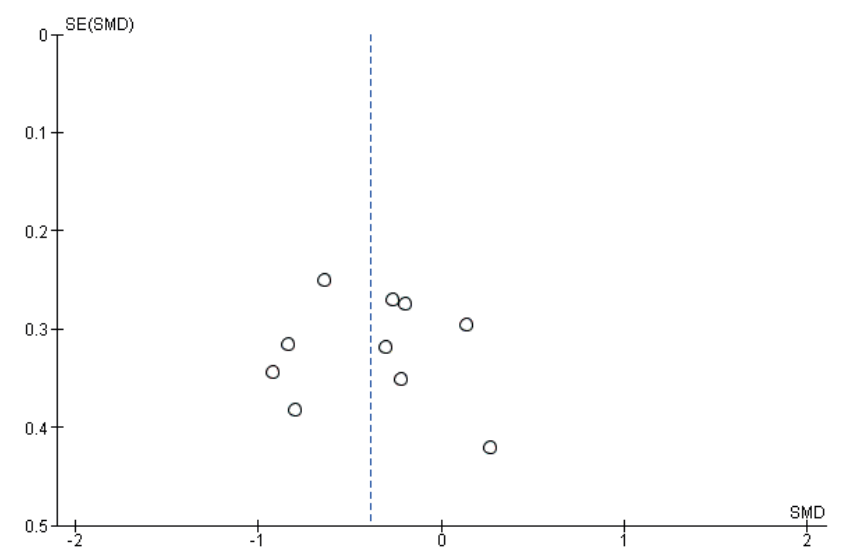

Figure 5. Visibility score funnel plot.

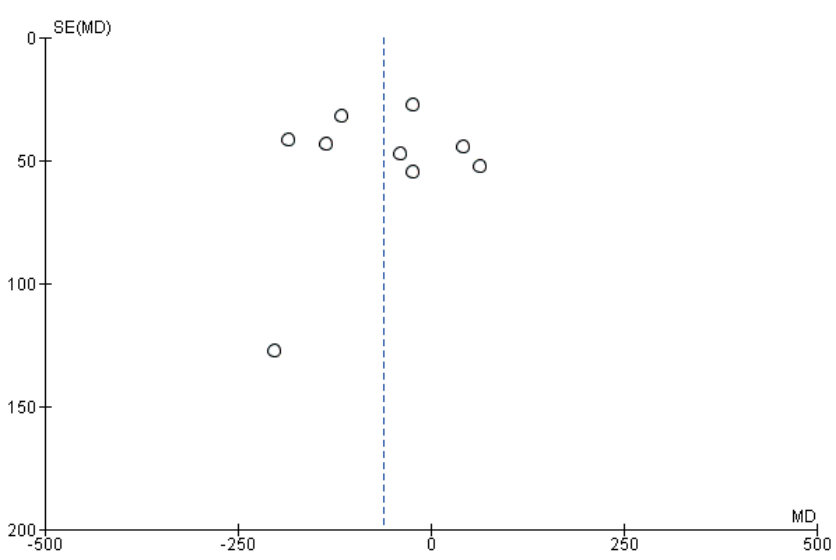

Figure 6. Estimated blood loss funnel plot.

$<0.001)^{(15)}$. However, our meta-analysis is the first to show a significant difference with regard to operative time or EBL. DeConde et al. had a total of nine studies in their meta-analysis but included studies that did not control for the short acting opioid between the TIVA and IA groups. We excluded those studies, but also included one study not captured by their search strategy, and six additional RCTs published after their meta-analysis. Thus, we were likely able to demonstrate a significant difference in $E B L$ and operative time because of the additional power that came with a greater number of studies and thus total subjects. While TIVA is a well-established technique, inhaled anaesthesia is more frequently utilized, and thus relative discomfort or inexperience with TIVA may be a potential disadvantage. Metaanalyses that studied the recovery profile of TIVA compared to IA have found reduced incidence of post-operative nausea and vomiting with TIVA ${ }^{(25)}$, and earlier recovery with IA, but overall no difference in time to discharge from the recovery room ${ }^{(25,26)}$. A study comparing desflurane-remifentanil to propofol-remifentanil for septorhinoplasty found to no difference in recovery profile or cost ${ }^{(27)}$.

\section{Limitations}

There was variability in the included studies that could have introduced confounding variables, such as use of topical vasoconstrictors and injected local vasoconstrictors. Also, the inhaled anaesthetics in these studies may have been titrated to higher dose than is common to maintain hypotension. The higher dose of inhalational anaesthetic may have led to greater blood loss and worse surgical field score by inducing vasodilation in the surgical field. There was also variability across studies in the scale used for surgical field assessment. Although this may be partially overcome with statistical techniques, a standardized and validated method of using these scales is not well-established, and reliability is low $(<0.70)$ without standardization ${ }^{(16)}$. The severity of sinus disease was also not consistently evaluated in these studies and is another potential confounding factor. Overall the quality of the included studies was not high and sample sizes were small.

\section{Conclusion}

Our search found that many randomized controlled trials comparing TIVA vs IA in endoscopic sinus surgery have been published. A meta-analysis of the pooled results from 12 studies suggests that TIVA with propofol is superior to IA for endoscopic sinus surgery with regards to surgical field quality, EBL, and operative time. A subgroup analysis further demonstrated that there may be a benefit only when remifentanil is used as the short acting opioid.

\section{Author contribution}

NRK: Designed the study, conducted the search, extracted data from each study, performed data and statistical analysis, and wrote the manuscript. LM: contributed to the design of the study, verified the search and data extraction, reviewed and edited the manuscript.

\section{Conflict of interest}

LM: Xhance Speaker's Bureau.

\section{References}

1. Ahn HJ, Chung SK, Dhong HJ, et al. Comparison of surgical conditions during propofol or sevoflurane anaesthesia for endoscopic sinus surgery. $\mathrm{Br} J$ Anaesth. 2008;100(1):50-4.

2. Cho K, Lee JY, Park SK, et al. Comparison of surgical conditions during propofol or des- flurane anesthesia for endoscopic sinus surgery. Korean J Anesthesiol. 2012;63(4):302-7.

3. Marzban S, Haddadi S, Mahmoudi Nia H Heidarzadeh A, Nemati S, Naderi Nabi B. Comparison of surgical conditions during propofol or isoflurane anesthesia for endoscopic sinus surgery. Anesth Pain Med. 2013;3(2):234-8
4. Little M, Tran V, Chiarella A, Wright ED. Total intravenous anesthesia vs inhaled anesthetic for intraoperative visualization during endoscopic sinus surgery: a double blind randomized controlled trial.Int Forum Allergy Rhinol. 2018;(10):1123-1126.

5. Milonski J, Zielinska-Blizniewska $H$ Golusinski W, Urbaniak J, Sobanski R, 
Olszewski J. Effects of three different types of anaesthesia on perioperative bleeding control in functional endoscopic sinus surgery. Eur Arch Otorhinolaryngol. 2013;270(7):2045-50.

6. Ankichetty SP, Ponniah M, Cherian V, et al. Comparison of total intravenous anesthesia using propofol and inhalational anesthesia using isoflurane for controlled hypotension in functional endoscopic sinus surgery. J Anaesthesiol Clin Pharmacol. 2011:27(3):328-32.

7. Beule AG, Wilhelmi F, Kuhnel TS, Hansen E, Lackner KJ, Hosemann W. Propofol versus sevoflurane: bleeding in endoscopic sinus surgery. Otolaryngol Head Neck Surg. 2007:136(1):45-50.

8. Chaaban MR, Baroody FM, Gottlieb O, Naclerio RM. Blood loss during endoscopic sinus surgery with propofol or sevoflurane: a randomized clinical trial. JAMA Otolaryngol Head Neck Surg. 2013;139(5):510-4.

9. Gomez-Rivera F, Cattano D, Ramaswamy $U$, et al. Pilot study comparing total intravenous anesthesia to inhalational anesthesia in endoscopic sinus surgery: novel approach of blood flow quantification.Ann Otol Rhinol Laryngol. . 2012;121(11):725-32.

10. Pavlin JD, Colley PS, Weymuller EA, Jr., Van Norman G, Gunn HC, Koerschgen ME. Propofol versus isoflurane for endoscopic sinus surgery. Am J Otolaryngol. 1999;20(2):96-101.

11. Sivaci R, Yilmaz MD, Balci C, Erincler T, Unlu H. Comparison of propofol and sevoflurane anesthesia by means of blood loss during endoscopic sinus surgery. Saudi Med J. 2004;25(12):1995-8.

12. Yoo HS, Han JH, Park SW, Kim KS Comparison of surgical condition in endoscopic sinus surgery using remifentanil combined with propofol, sevoflurane, or desflurane. Korean J Anesthesiol. 2010;59(6):377-82.

13. Kelly EA, Gollapudy S, Riess ML, Woehlck HJ, Loehrl TA, Poetker DM. Quality of surgical field during endoscopic sinus surgery: A systematic literature review of the effect of total intravenous compared to inhalational anesthesia. Int Forum Allergy Rhinol. 2013;3(6):474-81.

14. Boonmak P, Boonmak S, Laopaiboon M. Deliberate hypotension with propofol under anaesthesia for functional endoscopic sinus surgery (FESS). Cochrane Database Syst Rev. 2016;2016(10).

15. Deconde AS, Thompson CF, Wu EC, Suh JD. Systematic review and meta-analysis of total intravenous anesthesia and endoscopic sinus surgery. Int Forum Allergy Rhinol. 2013;3(10):848-54

16. Athanasiadis T, Beule A, Embate J, Steinmeier E, Field J, Wormald PJ. Standardized video-endoscopy and surgical field grading scale for endoscopic sinus surgery: a multi-centre study. Laryngoscope. 2008;118(2):314-9.

17. Boezaart AP, van der Merwe J, Coetzee A. Comparison of sodium nitroprusside- and esmolol-induced controlled hypotension for functional endoscopic sinus surgery. Can J Anaesth. 1995;42(5 Pt 1):373-6.

18. Stadnicka A, Flynn NM, Bosnjak ZJ, Kampine JP. Enflurane, halothane, and isoflurane attenuate contractile responses to exogenous and endogenous norepinephrine in isolated small mesenteric veins of the rabbit. Anesthesiology. 1993;78(2):326-34

19. Robinson BJ, Ebert TJ, O'Brien TJ, Colinco MD, Muzi M. Mechanisms whereby propofol mediates peripheral vasodilation in humans. Sympathoinhibition or direct vascular relaxation? Anesthesiology. 1997;86(1):64-72.

20. Haberer JP, Audibert G, Saunier CG, Muller C, Laxenaire MC, Hartemann D. Effect of propofol and thiopentone on regional blood flow in brain and peripheral tissues during normoxia and hypoxia in the dog. Clin Physiol.1993;13(2):197-207.

21. Van Aken $H$, Van Hemelrijck J. Influence of anesthesia on cerebral blood flow and cerebral metabolism: an overview. Agressologie. 1991;32(6-7):303-6.

22. Handa T, Onodera T, Honda Y, Koukita Y, Ichinohe T. Propofol-remifentanil is more effective than propofol-fentanyl in decreas- ing intraoperative blood loss during sagittal split ramus osteotomy. Bull Tokyo Dent Coll. 2016;57(3):169-73.

23. Gargiulo G, Cafiero T, Frangiosa A, et al Remifentanil for intraoperative analgesia during the endoscopic surgical treatment of pituitary lesions. Minerva Anestesiol. 2003;69(3):119-23, 24-6.

24. Kawano H, Manabe $S$, Matsumoto $T$, et al Comparison of intraoperative blood loss during spinal surgery using either remifentanil or fentanyl as an adjuvant to general anesthesia. BMC anesthesiol. 2013;13(1):46.

25. Gupta A, Stierer T, Zuckerman R, Sakima N, Parker SD, Fleisher LA. Comparison of recovery profile after ambulatory anesthesia with propofol, isoflurane, sevoflurane and desflurane: a systematic review. Anesth Analg. 2004:98(3):632-41.

26. Robinson BJ, Uhrich TD, Ebert TJ. A review of recovery from sevoflurane anaesthesia: comparisons with isoflurane and propofol including meta-analysis. Acta Anaesthesiol Scand. 1999;43(2):185-90.

27. Gokce BM, Ozkose Z, Tuncer B, Pampal K, Arslan D. Hemodynamic effects, recovery profiles, and costs of remifentanil-based anesthesia with propofol or desflurane for septorhinoplasty. Saudi Med J. 2007;28(3):358-63.

\author{
Nadeem R. Kolia \\ 601 Elmwood Avenue \\ Box 629 \\ Rochester \\ NY 14642 \\ USA \\ Tel: 585-276-5181 \\ Fax: 585-271-8552 \\ E-mail:nkolia@gmail.com
}

